\title{
Development of a Virtual Environment for Simulation of a 3D Road Profile Using OpenCRG and MATLAB GUI
}

\author{
Théophile Roch Ori ${ }^{1}, N^{\prime}$ Golo Mamadou Kone ${ }^{1}$, Sibiri Traore ${ }^{2}$ \\ ${ }^{1}$ Université Felix Houphouët Boigny de Cocody Laboratoire de Technologie, UFR SSMT, Cote d'Ivoire \\ ${ }^{2}$ Institut Pédagogique National de l'Enseignement Technique et Professionnel (IPNETP) Département de Génie Mécanique, \\ Cote d'Ivoire \\ Email: theophile.ori@univ-fhb.edu.ci
}

How to cite this paper: Ori, T.R., Kone, N'G.M. and Traore, S. (2021) Development of a Virtual Environment for Simulation of a 3D Road Profile Using OpenCRG and MATLAB GUI. Engineering, 13, 677-689. https://doi.org/10.4236/eng.2021.1312049

Received: September 23, 2021

Accepted: December 21, 2021

Published: December 24, 202

Copyright $\odot 2021$ by author(s) and Scientific Research Publishing Inc. This work is licensed under the Creative Commons Attribution International License (CC BY 4.0).

http://creativecommons.org/licenses/by/4.0/

\section{(c) (i) Open Access}

\begin{abstract}
In vehicle dynamics, there are wide applications concerning the simulation of vehicles on roads. These simulation applications relate to vehicle driving, ride comfort and durability. An accurate prediction of simulation results requires reliability and efficiency of road representations. The MATLAB graphical user interface module, called MATLAB GUI, is used to develop virtual simulation laboratories that allow the user to interact with a computer program using graphical objects. In this context, the aim of this article is to use the MATLAB OpenCRG suite of tools and the MATLAB GUI to develop a virtual environment for simulating a 3D road profile. A three-dimensional model of a pothole with variable parameters is developed and integrated into the $3 \mathrm{D}$ road profile.
\end{abstract}

\section{Keywords}

3D Road Profile, Pothole, OpenCRG, MATLAB GUI

\section{Introduction}

In the automotive industry, chassis designers integrate road profiles into the automotive design process. During this stage, engineers are challenged to predict vehicle load through computer modeling and simulation. The accuracy of these simulation results depends not only on the fidelity of the model but also on the excitation of the model, i.e. the road. The road is therefore the main excitement of the vehicle. Knowledge and modeling of the road profile are therefore essential especially for: 
- road quality analysis to deduce the consequences for passenger comfort,

- optimization of suspensions,

- improving vehicle safety and handling,

- a better understanding of vehicle dynamics.

According to [1], there are two main approaches to modeling a road profile which are: the deterministic approach and the stochastic approach. The simplest deterministic route profile model uses sinusoidal, rung, triangular, cardinal sin, square profiles [2]. The more complex stochastic road profile model characterizes road profiles as Markov chains [3]. Considering the road here as a random process, the spectral power density of the road surface is also used to model the road profile [4] [5].

Note that these road profiles are also obtained experimentally using measuring devices called profilometers such as the General Motor Profilometer (GMP) developed by General Motor in 1964 and also the APL (Longitudinal Profile Analyzer) developed by the LCPC (Central Laboratory of Bridges and Roads) in 1980 [6] [7]. Another semi-empirical approach consists in first obtaining, using a profilometer, the real road data and then in carrying out processing in order to digitize its data in a specific format to obtain a digital road model [8]. Recently the OpenCRG digital road model has been developed and has shown that it is possible to describe 3D digital road surfaces in a uniform and efficient format [9].

Road profiles with potholes are used in studies of vehicle dynamics simulation (for example during braking-acceleration, we compare the path during maneuvers with the responses to impact under a nest entry-hen, then we observe the state of the vehicle body which tends to feel significant vertical and rotational movements) and the design of alternative suspensions.

Although the same form of vehicle model can be used in many studies, the selected pothole dimensions and vehicle speed could be significantly different. For example, two alternative suspension designs or adjustments could have different performances under two different excitations of pothole models with different specified parameters (depth and duration). Thus, one suspension tuning design may work better than the other for the first pothole model but may produce worse shock isolation performance for the second pothole model. Hence the interest in developing several models of potholes was obtained by varying its parameters [7].

This article, therefore, offers a new software tool for three-dimensional simulation of an OpenCRG road profile which takes into account different excitations of pothole models represented in three dimensions obtained, by varying its parameters. In this contribution, we propose a $3 \mathrm{D}$ model of a route based on the OpenCRG model which contains a pothole type obstacle with variable parameters, modeled as a probabilistic distribution. All integrated thanks to the MATLAB graphical user interface module in a virtual simulation environment.

The article is organized as follows: Chapter 2 deals with the main types of road 
irregularities and their modeling methods. Chapter 3 offers the 3D simulation of a road without obstacles and that of a road with obstacles like potholes in the virtual environment. Chapter 4 concludes the article.

\section{Different Types of Route Irregularities}

The dynamics of road vehicles are generally evaluated under the effect of the main excitation of the vehicle, which is the road, even if the effect of other sources of excitation, such as aerodynamics, tire-wheel assemblies, chain. Kinematics and the engine, can be highlighted in the study. As such, it is well recognized that the road profiles used as input for the models of automobile chassis are road irregularities [10]. The main ones are the roughness of the road and the potholes.

\subsection{Road Roughness}

The roughness of the road, also called vertical displacement of the ground, is the road profile used to study the optimization of the suspensions and the vibratory comfort.

According to [11], the roughness of the road is modeled by a filtered white Gaussian noise of equation:

$$
\dot{z}(t)=-2 \pi f_{0} z(t)+2 \pi \sqrt{G G_{0} U_{0}(t)} \cdot w(t)
$$

or

z. Vertical displacement of the ground (m);

$f_{0}$ : Low cut-off frequency $(\mathrm{Hz})$;

$G$ : Unit coefficient $\left(\right.$ cycle $\left.\cdot \mathrm{m}^{-2} \cdot \mathrm{s}^{-1}\right)$;

$G_{0}$ : Road roughness coefficient $\left(\mathrm{m}^{3} /\right.$ cycle);

$U_{0}$ : Longitudinal speed of the vehicle $(\mathrm{m} / \mathrm{s})$;

$w(t)$ : Centered white Gaussian noise.

Another approach in [12] consists in characterizing the roughness of the road by its power spectral density noted PSD defined by:

$$
\operatorname{PSD}(\Omega)= \begin{cases}a(2 \pi \Omega)^{-2}, & \Omega \leq \frac{1}{2 \pi} \\ a(2 \pi \Omega)^{-1.5}, & \Omega>\frac{1}{2 \pi}\end{cases}
$$

with:

a: Geometric spatial mean;

$\Omega$ : Spatial frequency (cycles / $\mathrm{m}$ ).

According to [10], the roughness of the road can also be modeled as a Laplace or hybrid process (combination of the Gaussian model and the Laplace model).

\subsection{Pothole}

Different definitions of road potholes have been described in the literature, including [13]: 
A pothole can be defined as any localized loss of material or depression on the surface of a sidewalk.

A pothole is a bowl-shaped hole of various sizes on the pavement surface. The minimum dimension of the plan (diameter) is $150 \mathrm{~mm}$. The degrees of severity are:

- Weak: less than $25 \mathrm{~mm}$ deep;

- Moderate: between 25 - $50 \mathrm{~mm}$ deep;

- Top: more than $50 \mathrm{~mm}$ deep.

A cavity in the road surface that has an average diameter of $150 \mathrm{~mm}$ or more and a depth of $25 \mathrm{~mm}$ or more.

\subsection{Mathematical Modeling}

A variety of different pothole designs have been considered in the literature, which could be broadly classified as one of the following three types [13]:

- Smooth: pothole models with continuous first and second-order derivatives (displacement, speed and acceleration) in the open interval or duration of the pothole, including half-sine, shed sinus, cycloid, ellipse, polynomial, U-turn, etc.

- Not smooth: pothole models with continuous displacement curve only, in the open time interval, including triangular, trapezoidal, rectangular, etc.

Statistics: pothole models described by a probability distribution, such as a rounded pulse, which can be represented by:

$$
z(t)=A\left(\pi \frac{t}{T_{c}} \mathrm{e}^{1-\pi \frac{t}{T_{c}}}\right)^{2}
$$

With:

A: Constant;

$T_{c}$ : The characteristic duration so that the area under the impulse rounded in the interval $\left[0, T_{c}\right]$ is approximately $95 \%$ of the total surface of the pothole.

Another approach in [14] is to model potholes as sudden and transient inputs. The dimensions of potholes are effective parameters in estimating vehicle damage. The equation that specifies the potholes of the road can be written as follows:

$$
z(t)=\left\{\begin{array}{lc}
-\frac{t}{2} & t<0.1 \\
-h & 0.1<t<0.4 \\
\frac{-0.1+(t-0.4)}{2} & 0.4<t<0.5
\end{array}\right.
$$

with:

$h$ : The depth of the pothole (m);

$t$. Time (s).

In this article, we use the statistical model given by Equation (2.3) as a pothole model. The three-dimensional representation in space of this equation is obtained by using parametric equations with time as parameters. 


$$
\left\{\begin{array}{l}
x=t * \cos (\theta) \\
y=t * \sin (\theta)
\end{array}\right.
$$

with:

$(x, y)$ : Spatial parameters;

$t$. Time parameters;

$\theta$ : Passage angle.

The 3D model of the pothole in Equation (2.3) is:

$$
z(x, y)=h\left(\pi \frac{\sqrt{\left(x-x_{0}\right)^{2}+\left(y-y_{0}\right)^{2}}}{T_{c}} \mathrm{e}^{1-\pi \frac{\sqrt{\left(x-x_{0}\right)^{2}+\left(y-y_{0}\right)^{2}}}{T_{c}}}\right)^{2}
$$

with:

h: Pothole depth (m);

$T_{c}$ Characteristic duration (s);

$\left(x_{0}, y_{0}\right)$ : Spatial position of the pothole.

\section{Description of the Virtual Simulation Environment}

The road modeling techniques described in the previous sections have all been implemented in software. This tool, which we called RoadSIM, was created with the GUI (Graphical User Interface) of MATLAB.

RoadSIM has an easy-to-use interface and allows a user to choose the type of road model to model and then obtain the 3D profile of a barrier-free road and the $3 \mathrm{D}$ profile of a road with a nest-type obstacle. The interface is shown in Figure 1.

\subsection{Simulation of an Obstacle-Free Route}

A road without obstacles (a good road) has a significant vertical displacement of

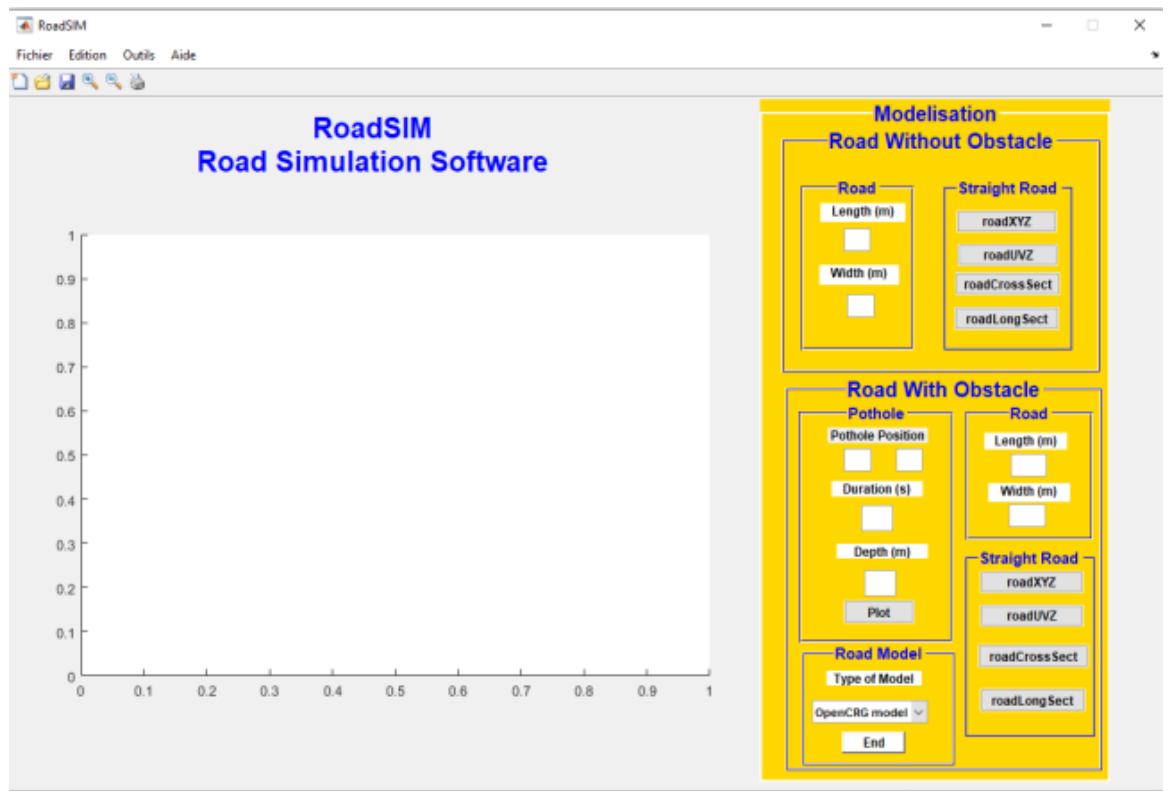

Figure 1. RoadSIM Software. 
the ground. As stipulated in [15], a good road is not smooth but has a vertical displacement of the lower ground at $2 \mathrm{~cm}$.

- The CRG XYZ road surface: Clicking on the road XYZ button represents the road in a curved $X Y$ grid with the $Z$-axis as elevation (Figure 2).

- CRG UVZ road surface: Clicking on the road UVZ button represents the road in a curved UV grid with the Z-axis as elevation (Figure 3).

- Road surface CRG Cross Section: Clicking on the roadCrossSect button represents the cross-section of the elevation grid (Figure 4). We can see on this figure vertical displacement of the ground stochastically.

- CRG Long Section road surface: Clicking on the roadLongSect button represents the longitudinal section of the elevation grid (Figure 5). Here also we can see the vertical displacement of the ground in a stochastic way.

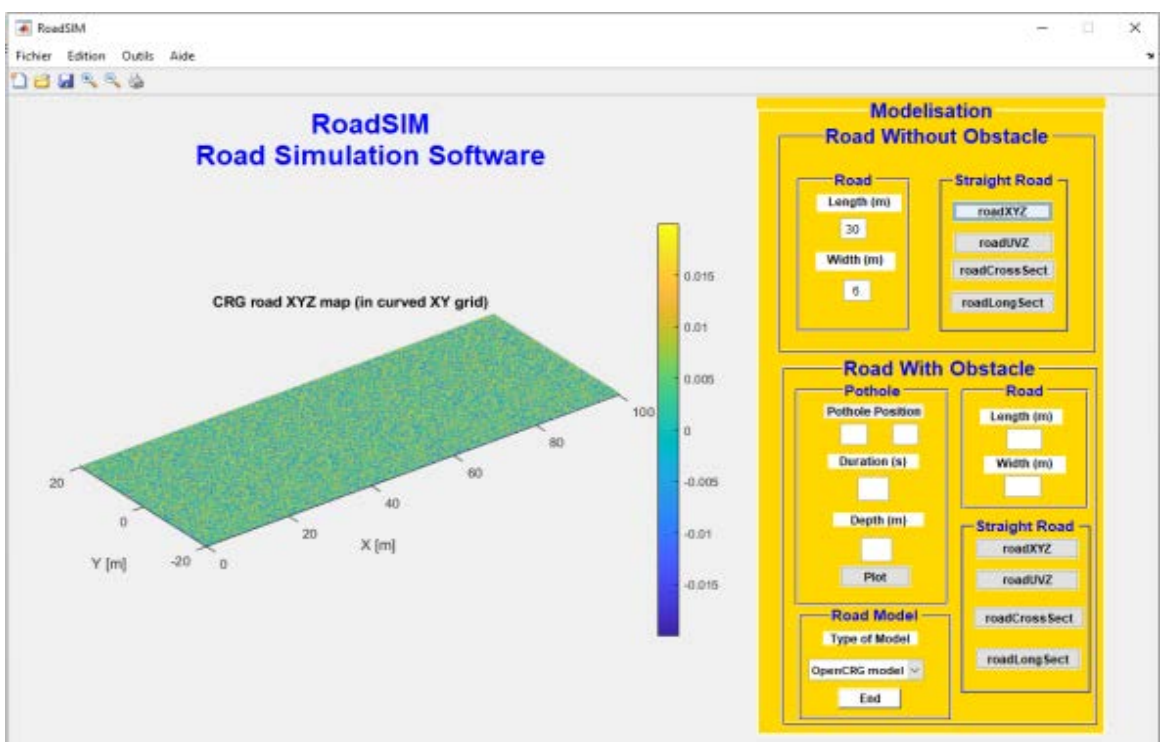

Figure 2. Curved $\mathrm{XY}$ grid route with the $\mathrm{Z}$ axis as elevation.

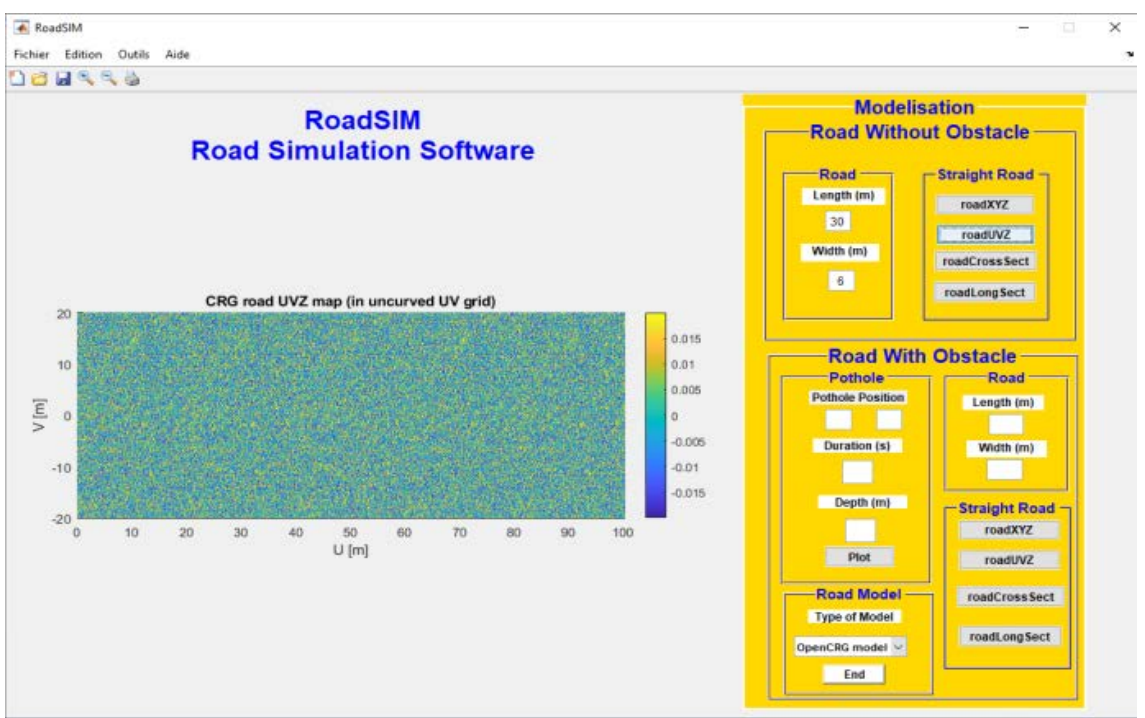

Figure 3. Curved UV grid route with $\mathrm{Z}$ axis as elevation. 


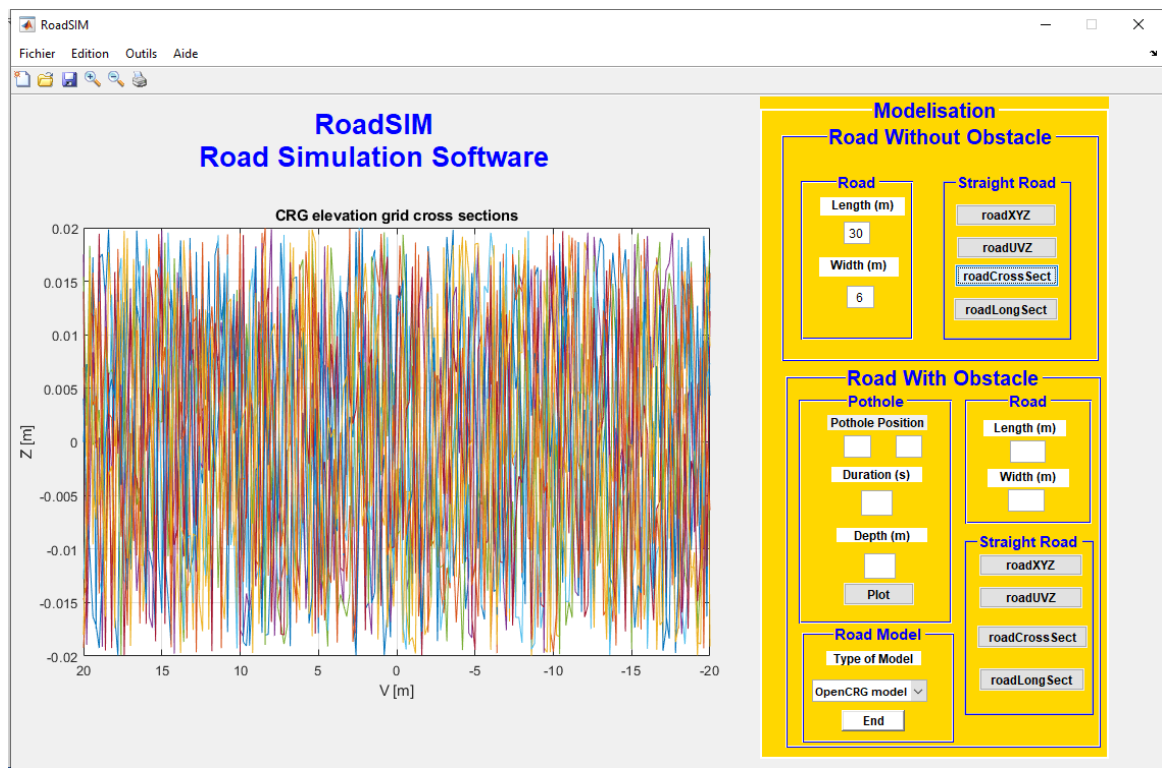

Figure 4. Curved UV grid route with $\mathrm{Z}$ axis as elevation.

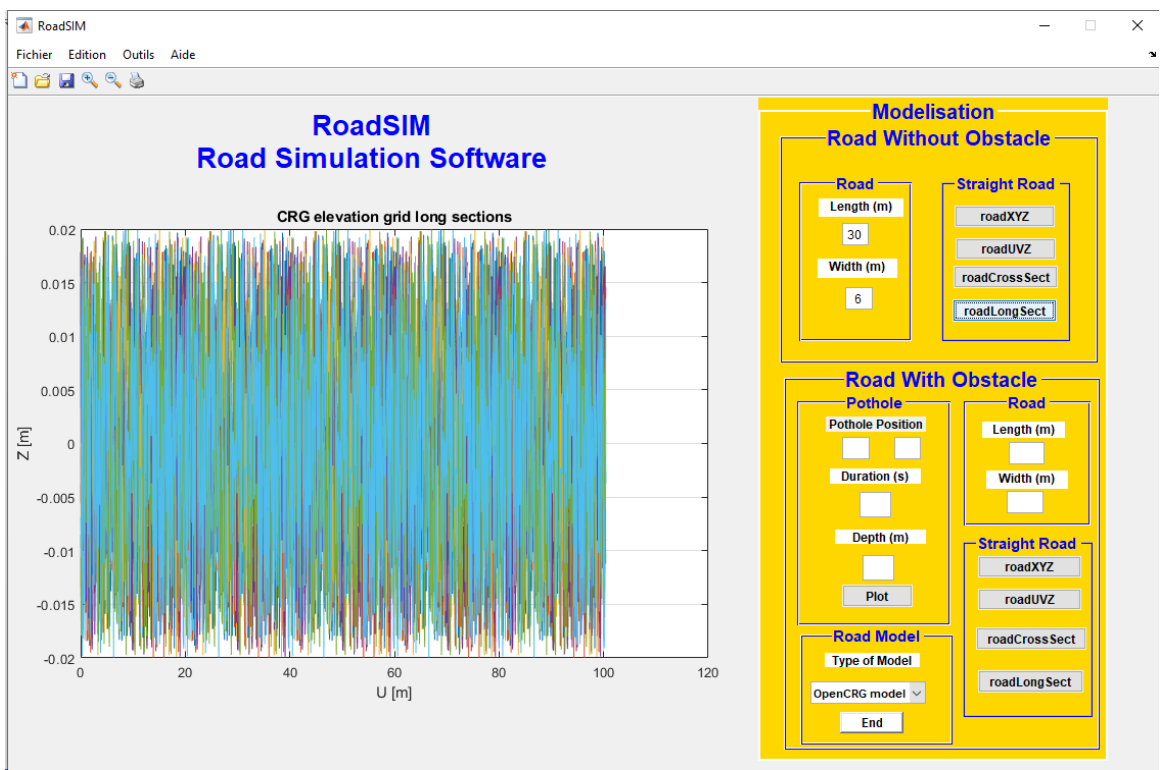

Figure 5. Curved UV grid route with $\mathrm{Z}$ axis as elevation.

\subsection{Simulation of a Road with a Pothole Type Obstacle}

\subsubsection{D Representation of a Pothole}

In Road SIM, the three-dimensional representation of the pothole modeled from Equation (2.6), is given in Figure 4. We took as parameters of the hole $h=0.08$ $\mathrm{m}, T_{c}=1.7 \mathrm{~s}$ and placed the pothole has the spatial position: $\left(x_{0}, y_{0}\right)=(0,0)$.

By varying the parameters of the hole, taking $h=0.15 \mathrm{~m}, T_{c}=2 \mathrm{~s}$ and placing the pothole at the spatial position: $\left(x_{0}, y_{0}\right)=(1,1)$, we obtain a second threedimensional representation of the pothole in Figure 7.

By integrating the potholes in Figure 6 and Figure 7 into the OpenCRG road model, we obtain two road profiles with the following potholes. 


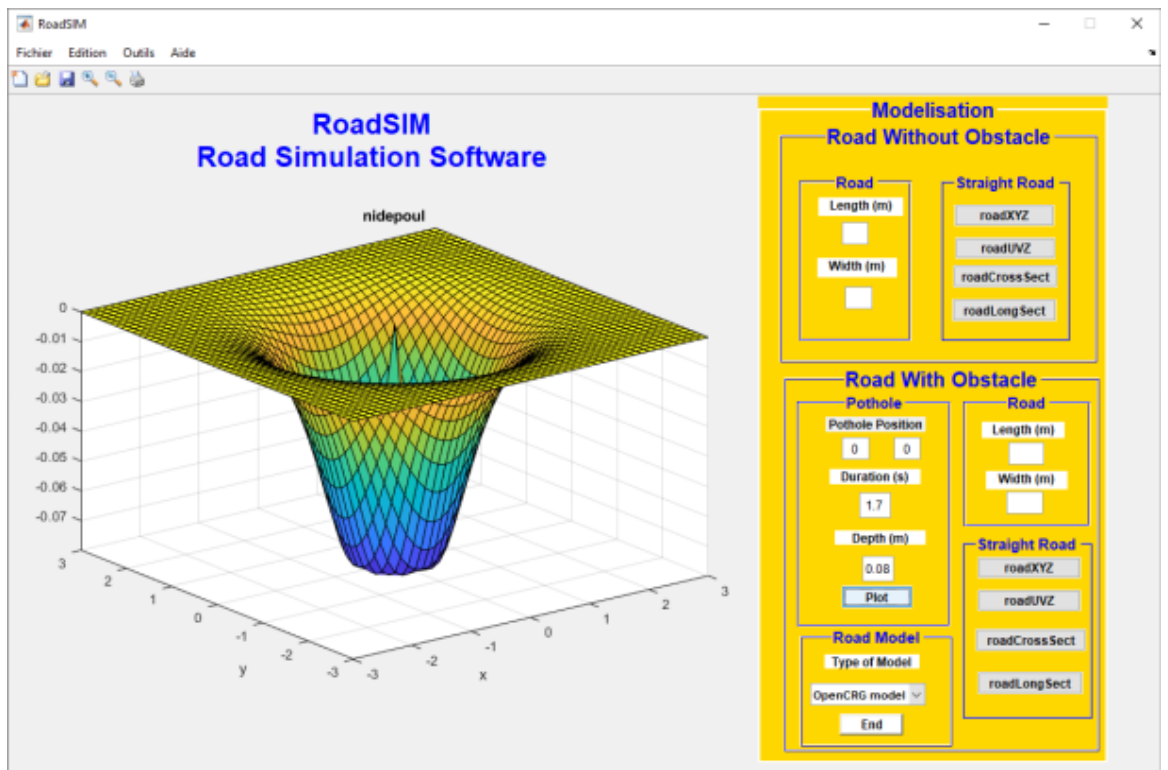

Figure 6. Pothole with: $h=0.08 \mathrm{~m}, T_{c}=1.8 \mathrm{~s}$ and $\left(x_{0}, y_{0}\right)=(0,0)$.

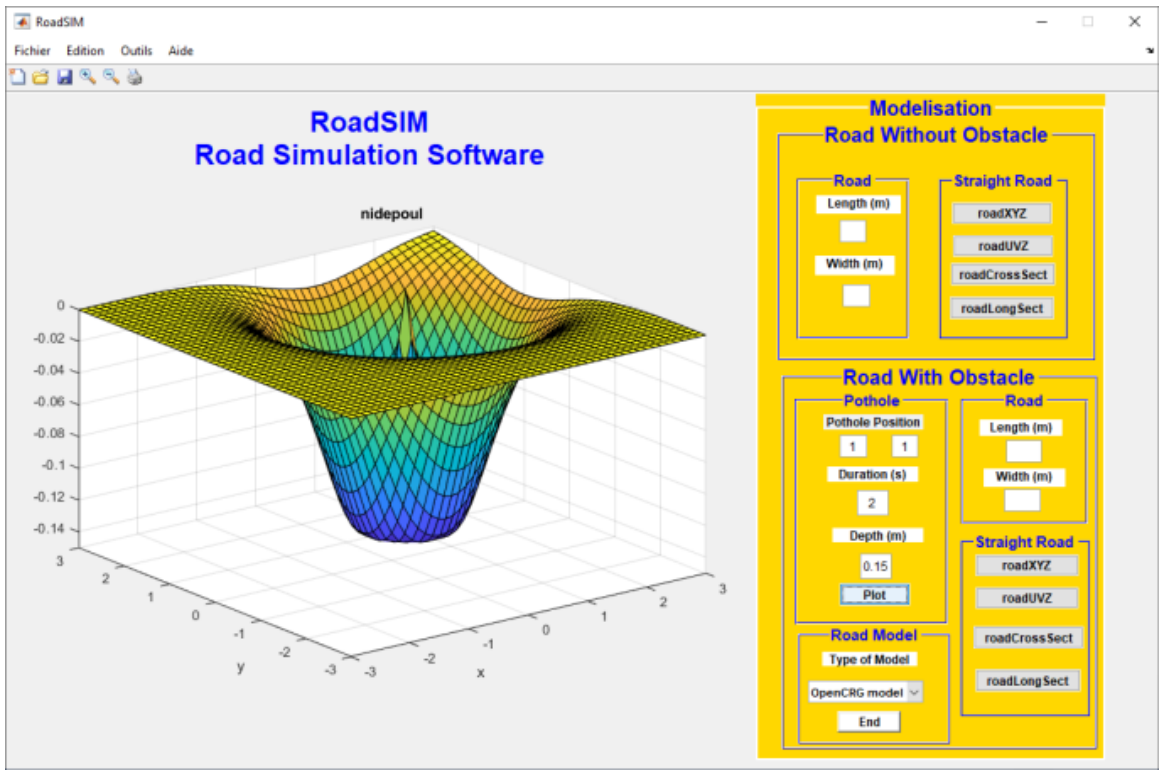

Figure 7. Pothole with: $h=0.15 \mathrm{~m}, T_{c}=2 \mathrm{~s}$ and $\left(x_{0}, y_{0}\right)=(1,1)$.

\subsubsection{First 3D Road Profile with Pothole: $h=0.08 \mathrm{~m}$ and $T_{c}=1.8 \mathrm{~s}$}

The CRG XYZ road surface: Clicking the road XYZ button represents the curve $\mathrm{XY}$ grid road with the $\mathrm{Z}$-axis as elevation (Figure 8).

CRG UVZ road surface: Clicking on the road UVZ button represents the road in a curved UV grid with the Z-axis as elevation (Figure 9).

- Cross-section: Clicking on the roadCrossSect button represents the cross-section of the road (Figure 10).

- Longitudinal profile: Clicking on the roadLongSect button represents the longitudinal profile along the route (Figure 11).

The cross-section of the road does not allow us to see the depth of the hole. By 


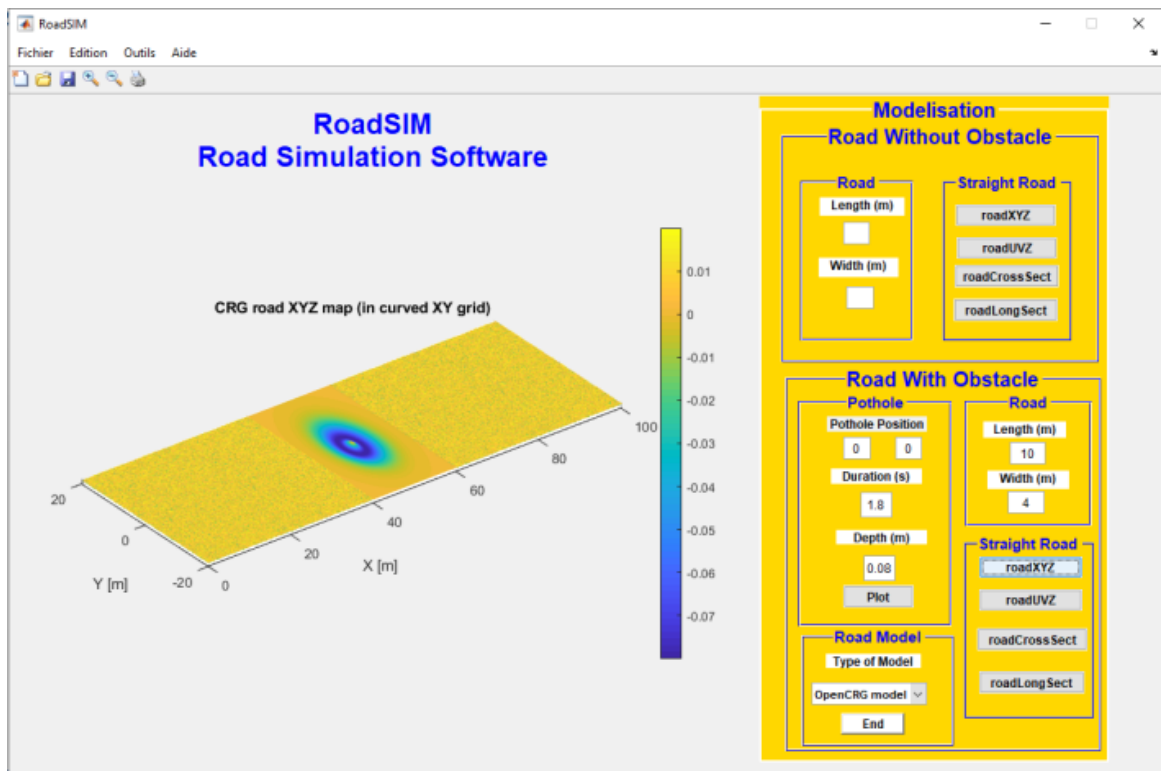

Figure 8. Curved $\mathrm{XY}$ grid route with the Z-axis as elevation.

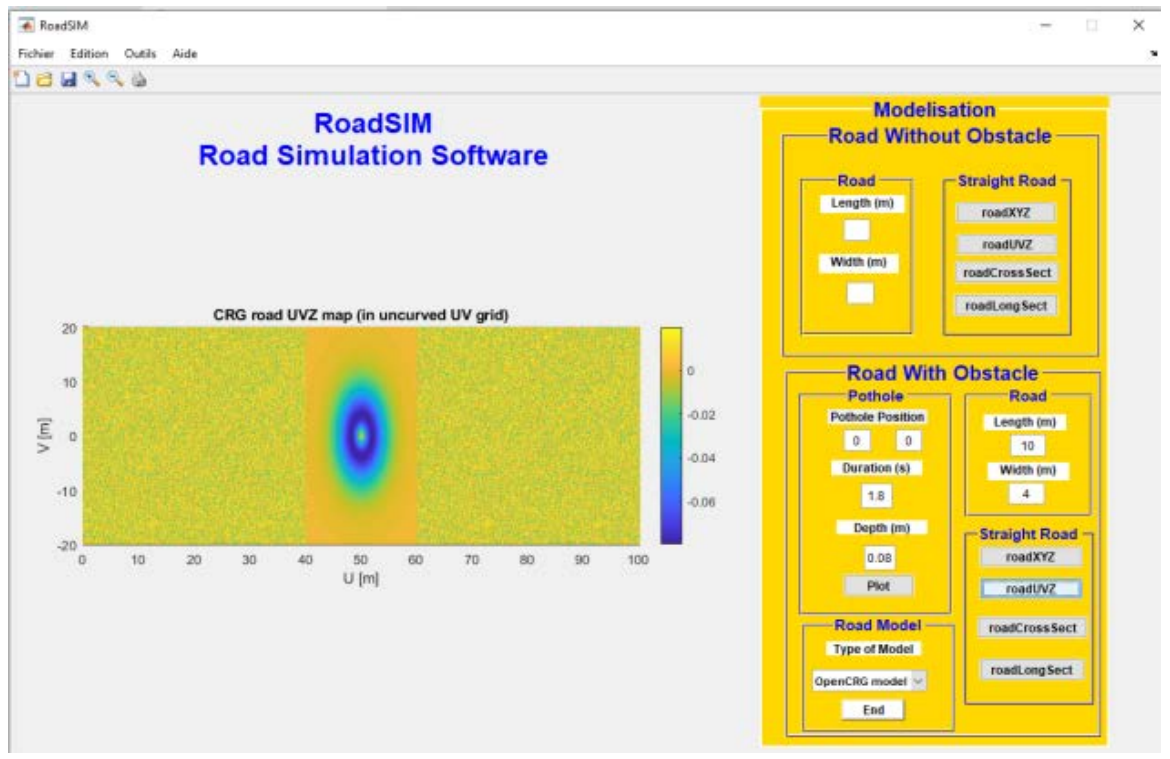

Figure 9. Curved UV grid route with Z-axis as elevation.

cons on the longitudinal profile, we can see the depth of the pothole. This is explained by the fact that the vertical displacement of the ground seen along the lateral axis (i.e. along the width of the road) is denser than the vertical displacement of the ground seen along the longitudinal axis (along the entire length of the road).

3.2.3. Second 3D Road Profile with Pothole: $h=0.15 \mathrm{~m}$ and $T_{c}=2 \mathrm{~s}$

- The CRG XYZ road surface: Clicking on the road XYZ button represents the curve XY grid road with the $\mathrm{Z}$-axis as elevation (Figure 12).

- CRG UVZ road surface: Clicking on the road UVZ button represents the road in a curved UV grid with the Z-axis as elevation (Figure 13). 


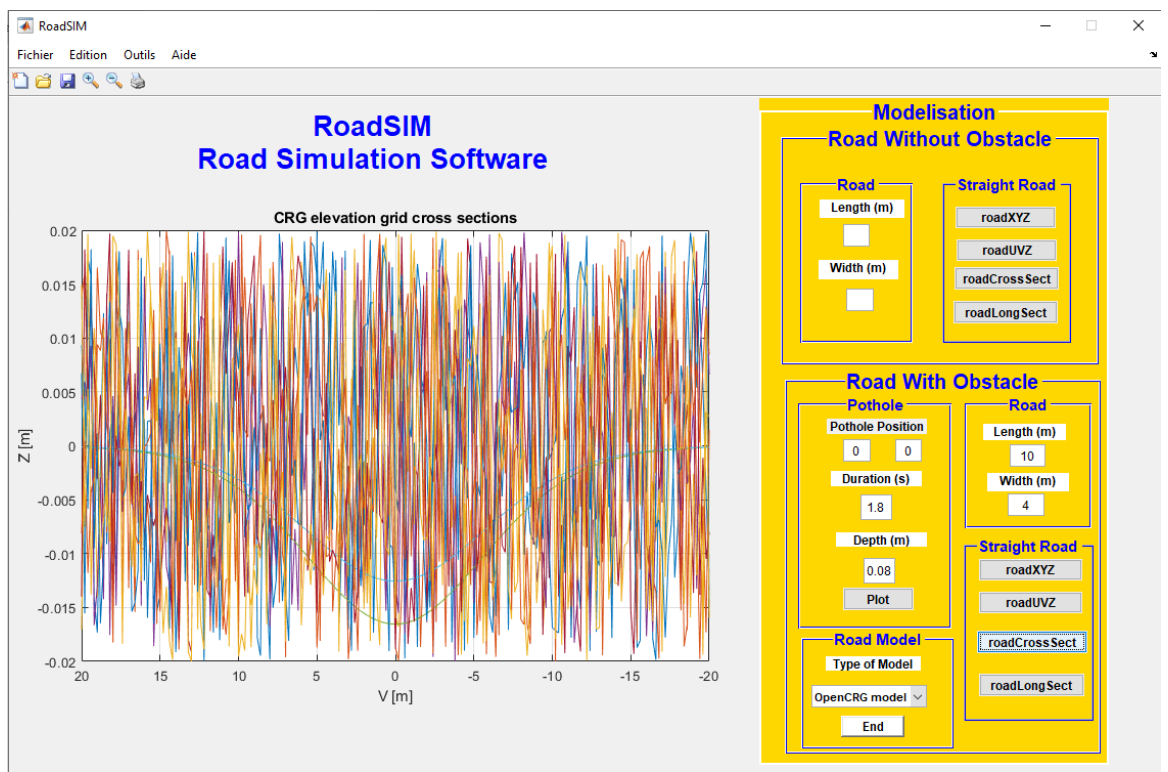

Figure 10. Profile across the road.

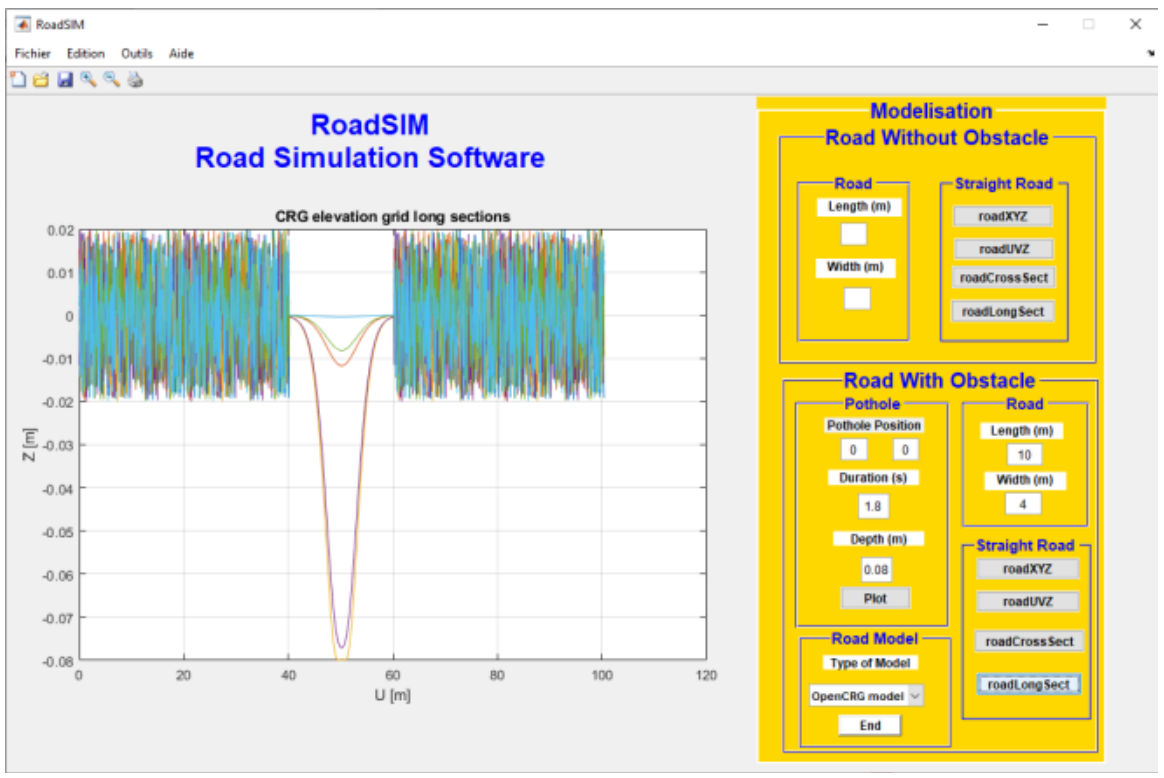

Figure 11. Profile along the road.

- Longitudinal profile: Clicking on the roadCrossSect button represents the longitudinal profile of the road (Figure 14).

- Longitudinal profile: Clicking on the roadLongSect button represents the longitudinal profile of the road (Figure 15).

\section{Conclusion and Perspectives}

In our study, we have developed a virtual environment for simulating three-dimensional road surfaces with pothole-type obstacles.

As a route model, we opted for the OpenCRG digital model, then we used the Matlab GUI to design the graphical interface. The pothole was considered a 


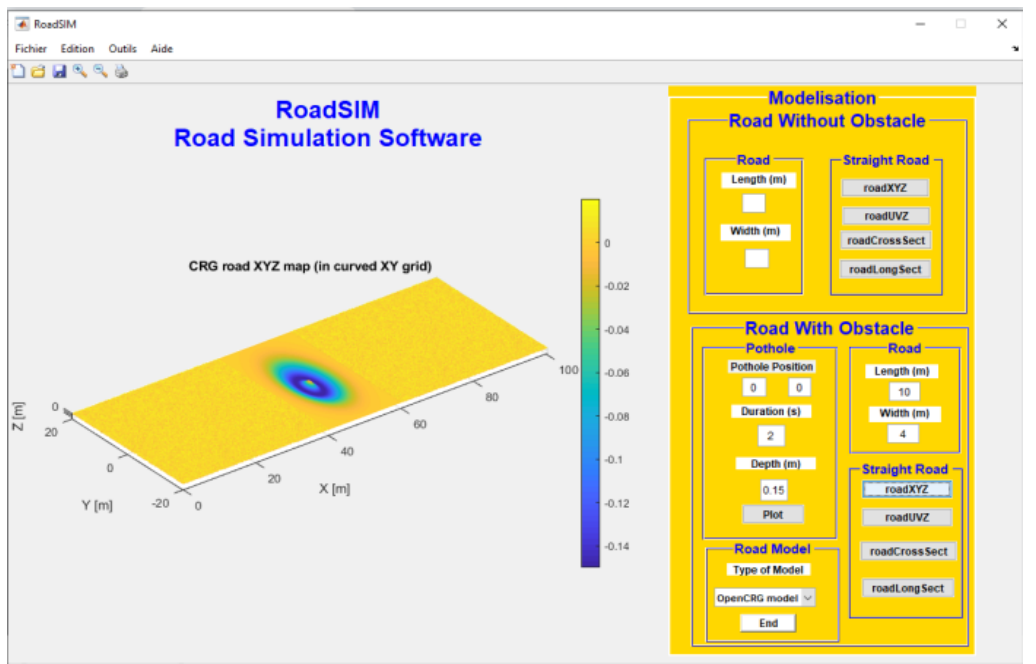

Figure 12. Curved XY grid route with the $\mathrm{Z}$ axis as elevation.

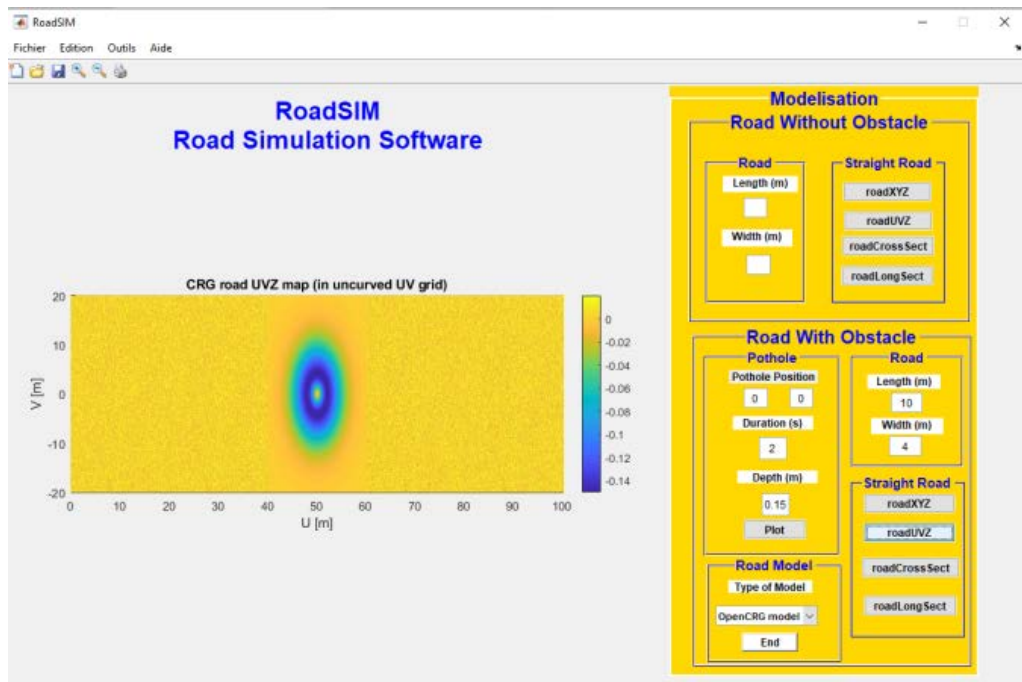

Figure 13. Curved UV grid route with $\mathrm{Z}$-axis as elevation.

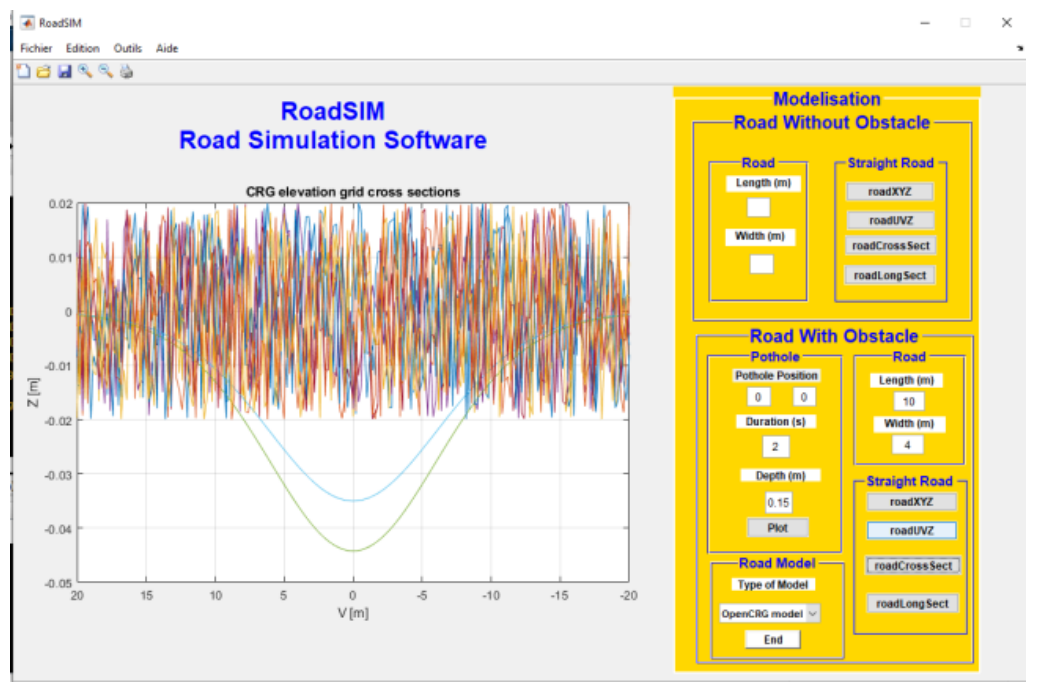

Figure 14. Profile across the road. 


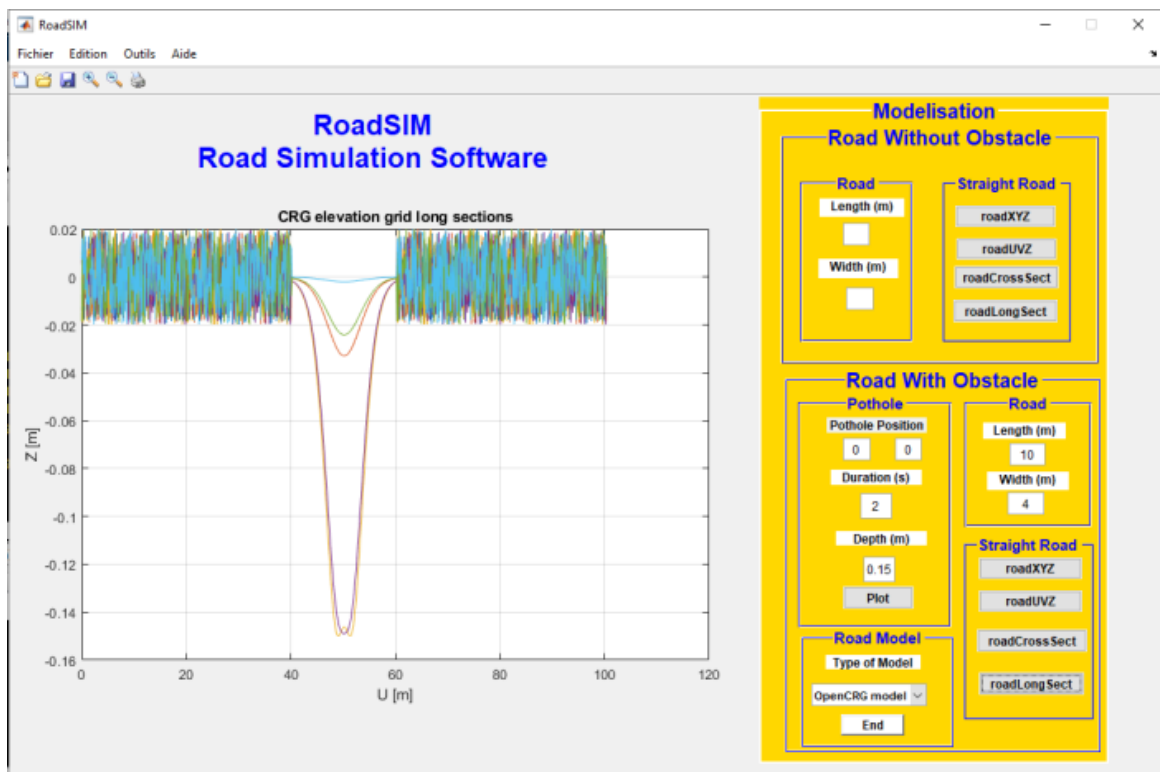

Figure 15. Profile along the route.

probabilistic distribution whose parameters varied.

This allowed us to obtain a 3D road profile with a pothole-type obstacle whose parameters are variable. A simulation study aimed at studying the effect of the pothole, the parameters of which vary, on the response of a vehicle approaching the obstacle will be carried out in future work.

\section{Conflicts of Interest}

The authors declare no conflicts of interest regarding the publication of this paper.

\section{References}

[1] Rill, G. (2011) Road Vehicle Dynamics: Fundamentals and Modeling. CRC Press, Boca Raton. https://doi.org/10.1201/9781439897447

[2] Channe, S.S. and Kshirsagar, S.D. (2013) Modeling and Simulation of a Suspension System for Different Road Disturbances. International Journal of Science and Research, 2319-7064.

[3] Ferris, J.B. (2004) Characterizing Road Profiles as Markov Chains, International. International Journal of Vehicle Design, 36, 103-115. https://doi.org/10.1504/IJVD.2004.005351

[4] Davis, B.R. and Thompson, A.G. (2001) Power Spectral Density of Road Profiles. Vehicle System Dynamics, 35, 409-415. https://doi.org/10.1076/vesd.35.6.409.2039

[5] Sharp, R.S. and Crolla, D.A. (1987) Road Vehicle Suspension System Design-A review. Vehicle System Dynamics, 16, 167-192. https://doi.org/10.1080/00423118708968877

[6] Imine, H., Delanne, Y. and M'Sirdi, N.K. (2006) Road Profile Input Estimation in Vehicle Dynamics Simulation. Vehicle System Dynamics, 44, 285-303. https://doi.org/10.1080/00423110500333840

[7] Imine, H., Delanne, Y. and M'Sirdi, N.K. (2005) Road Profile Inputs for Evaluation 
of the Loads on the Wheels. Vehicle System Dynamics, 43, 359-369. https://doi.org/10.1080/00423110500108945

[8] Ressel, W., Sanchez, M.M. and Tejkl, K. (2015) Dynamicmeasurements and Simulation of Road Surface Characteristics. In: Bargende, M., Reuss, H.C., Wiedemann, J., Eds., Internationales Stuttgarter Symposium Proceedings, Springer Vieweg, Wiesbaden. https://doi.org/10.1007/978-3-658-08844-6_64

[9] Schmeitz, Versteden, W. and Eguchi, T. (2011) Road Load Simulation Using the MF-Swift Tire and OpenCRG Road Model. SAE Technical Paper. https://doi.org/10.4271/2011-01-0190

[10] Bogsjö, K., Podgorski, K. and Rychlik, I. (2012) Models for Road Surface Roughness. Vehicle System Dynamics, 50, 725-747. https://doi.org/10.1080/00423114.2011.637566

[11] Yu, F. and Crolla, D.A. (1998) An Optimal Self-Tuning Controller for an Active Suspension. Vehicle System Dynamics, 29, 51-65. https://doi.org/10.1080/00423119808969366

[12] Gonzalez, O'Brien, E.J., Li, Y.Y. and Cashell, K. (2008) The Use of Vehicle Acceleration Measurements to Estimate Road Roughness. Vehicle System Dynamics, 46, 483-499. https://doi.org/10.1080/00423110701485050

[13] Cao, D., Song, X. and Ahmadian, M. (2011) Editors Perspectives: Road Vehicle Suspension Design, Dynamics, and Control. Vehicle System Dynamics, 49, 3-28. https://doi.org/10.1080/00423114.2010.532223

[14] Zehsaz, M., Sadeghi, M.H., Ettefagh, M.M. and Hassannejad, R. (2014) Fatigue Strength of a Chassis of a Semi-Heavy Truck under Dynamic Loads Due to Real Road Roughness. Transactions of Famena, XXXVIII, 4

[15] Ori, T.R. (2001) Active Suspensions and Dynamic Behavior of Vehicles during Braking. PHD Thesis, Ecole Centrale Lyon, Écully.

\section{Notations}

z. Road height $(\mathrm{m})$

$G$ : Unit coefficient $\left(\right.$ cycle $\left.\cdot \mathrm{m}^{-2} \cdot \mathrm{s}^{-1}\right)$

$G_{0}$ : Road roughness coefficient ( $\mathrm{m}^{3} /$ cycle)

$U_{0}$ : Longitudinal speed of the vehicle $(\mathrm{m} / \mathrm{s})$

$w(t)$ : Centered white Gaussian noise

f. Frequency $(\mathrm{Hz})$

$f_{0}$ : Cutoff frequency $(\mathrm{Hz})$

$A$ : Constants $W_{1} W_{2}$

PSD: Power spectral density of the ground displacement

$t$. Time (s)

a: Geometric spatial mean

$\Omega$ : Spatial frequency (cycles / $\mathrm{m}$ )

$T_{c}$ : Characteristic time (s)

$h$ : Pothole depth (m)

$\left(x_{0}, y_{0}\right)$ : Spatial position of the pothole 